INTERNATIONAL JOURNAL OF RESEARCHES IN BIOSCIENCES, AGRICULTURE AND TECHNOLOGY (C) VISHWASHANTI MULTIPURPOSE SOCIETY (Global Peace Multipurpose Society) R. No. MH-659/13(N) www.vmsindia.org

\title{
INNOVATIVE APPROACH FOR SOLAR RADIATION MEASUREMENT AND DATA ACQUISITION USING eXPEYES
}

\author{
V. S. Rahangadale and A. K. Mittra \\ 1,Engineering, M.I.E.T. Gondia, M. S. India \\ vijayaspr97@rediffmail.com
}

\begin{abstract}
:
Measurement and estimation of solar radiation is essentially required in the domain of the photovoltaic power station for planning as well as it is greatly required in Agriculture domain for Water scheduling. This paper presents an overview of systems used for solar radiation measurement also throw light on the current trends in solar radiation estimation. Till date different soft computing techniques have been proposed by researchers such as artificial neural networks, fuzzy predictors, evolutionary and genetic algorithms still efficient solar radiation time series prediction is regarded as a challenging task for researchers both in the past and at present. The paper presents a proposal for innovative solar radiation data acquisition system.
\end{abstract}

Keywords: Solar radiation, Data acquisition, exp EYES board

\section{Introduction}

Solar radiation is the radiant energy emitted by the Sun in the form of electromagnetic waves. As the radiation penetrates the atmosphere, some of the radiation is scattered, reflected or absorbed by the atmospheric gases, clouds and dust. The amount of radiation reaching a horizontal plane is known as the solar radiation. Because the sun emits energy by means of electromagnetic waves characterized by short wavelengths, solar radiation is also referred to as shortwave radiation. Solar radiation is also known as global radiation, meaning that it is the sum of direct shortwave radiation from the sun and diffuse sky radiation from all upward angles.

\section{Current trends in solar radiation Data acquisition}

Early works in the field of solar radiation data acquisition and estimation have been published in the literature. Some of the most significant papers are remembered, starting with [1] which is consists of two scientific pyranometers and an on-line computer data acquisition system. The values of total and diffuse solar radiation are stored on a server, in a mysql database, using high precision, original data acquisition equipment and different original software applications. A flexible web based interface, was developed to interrogate the database and to extract relevant data, based on that different user selected periods. Average values for the solar radiation components are computed, together with total solar radiant heat for the user selected periods.

A low cost microcontroller based data logger system for solar radiation (in Watt/m2) measurement had been developed in [3]. The measured radiation is displayed on an LCD and automatically gets store into the EEPROM of the microcontroller after a regular interval of 5 minutes. The system works with an error of less than $5 \%$. The hardware design and operation of a battery-powered microcontroller-based data acquisition system (DAS) for unattended remote measurements are presented in [5]. Sol Data silicon-cell pyranometer is used as the solar radiation sensor. Field tests and comparisons of this measurement system against the standard Eppley precision spectral pyranometer (PSP) had shown a slightly nonlinear correlation and that the accuracy of this measurement system as applied to solar radiation monitoring is typically $\pm 13 \mathrm{~W} / \mathrm{m}^{2}$

The system which can measure the incident power per unit area and can also give the duration of maximum sunshine is developed in [4]. The system comprises of photodiode OPT 101, Servo Motor is used to track the sun so that Direct Normal Incident radiation is only measured.

\section{Noteworthy contribution in Solar Radiation measurement}

In [2] solar radiation sensing transducer, a component of a Multi-sensor system is developed which consists of a structure of green light emitting diodes. The position and "status" of the Sun and the global and diffuse components of solar radiation are estimated by processing the data gathered from the rosette of nine high speed and high sensitive PIN photodiodes. The system output is compared with a thermopile solar detector (Kipp \& Zonen CM11) global output also the comparison between the voltage output coming from two different PIN photodiodes in different light conditions is carried out (shadow and no shadow state) which gives the diffuse and global 
irradiance ratio $(\mathrm{R})$.

The system which measures the incident power per unit area and will also give the duration of maximum sunshine is developed in [4]. The system comprises of photodiode OPT 101, Servo Motors is used to track the sun so that Direct Normal Incident radiation is only measured. Solar radiation measurement is carried out in [6] is with $2.3 \%$ error. Reading data is buffered and viewed over Ethernet connection over a Public Local area LAN system.

An intelligent sensor had been developed in [13] for acquiring temperature, solar radiation data and estimate cloudiness indexes, and use these measured values to predict temperature and solar radiation in a close future. A CCTV camera with a fish-eye lens, for sky images acquisition and a pyranometer, for regular measurements of solar radiation is used. System is developed on Arduino platform. Neural networks of the type
NARX, which use the acquired data to forecast the cloudiness index, solar radiation and temperature, in the next four hours period.

\section{Solar Radiation Measu rement systems}

Pyranometer and pyrheliometer are used for measuring short wave radiation in the range of $0.3 \mu \mathrm{m}-4.0 \mu \mathrm{m}$ Pyrgeometer is used to measure Long wave radiation in the range $4 \mu \mathrm{m}$ $100 \mu \mathrm{m}$ and pyradiometer used to measure net radiation from $0.3 \mu \mathrm{m}$ to $100 \mu \mathrm{m}$. Table 1 shows the classification of instruments based on the radiation of different wavelength. These instruments need to install in very specific and precise manner. These instruments are usually installed in Meteorological departments and data of that station is recorded. On the basis of recorded data at one station, data for the nearby places is predicted. There is a need to develop portable and cost effective system for solar radiation data acquisition system.

Table. 1- Instruments used for solar radiation measurement

\begin{tabular}{|c|c|}
\hline Parameter & Instruments used \\
\hline \multicolumn{2}{|l|}{ Short Wave $(0.3 \mu-4.0 \mu)$} \\
\hline Direct solar irradiance & Angstrom and Thermoelectric Pyrheliometers \\
\hline Global solar irradiance & Thermoelectric Pyranometer \\
\hline Diffuse solar irradiance & Thermoelectric Pyranometer with shading ring \\
\hline Reflected solar irradiance & Inverted Pyranometer \\
\hline Solar spectral irradiance and turbidity & Sunphotometer \\
\hline \multicolumn{2}{|l|}{ Long Wave $(4 \mu-100 \mu)$} \\
\hline Net Terrestrial Radiation & Angstrom Pyrgeometer \\
\hline \multicolumn{2}{|l|}{ Total $(0.3 \mu-100 \mu)$} \\
\hline Upward or downward & Radiation Pyradiometer \\
\hline Net Radiation & Net Pyradiometer \\
\hline
\end{tabular}

\section{Proposed System for Solar Radiation Data Acquisition}

This paper presents a proposal for an innovative solar radiation data logger. PIN sensor will be used as sensing element for capturing short wave solar radiation. expEYES will be used as an interface between sensor and Python Interpreter. expEyes will record voltage in proportion to solar radiation. Python program will be used to convert the recorded data in proportional to solar radiation in $\mathrm{W} / \mathrm{m}^{2}$.

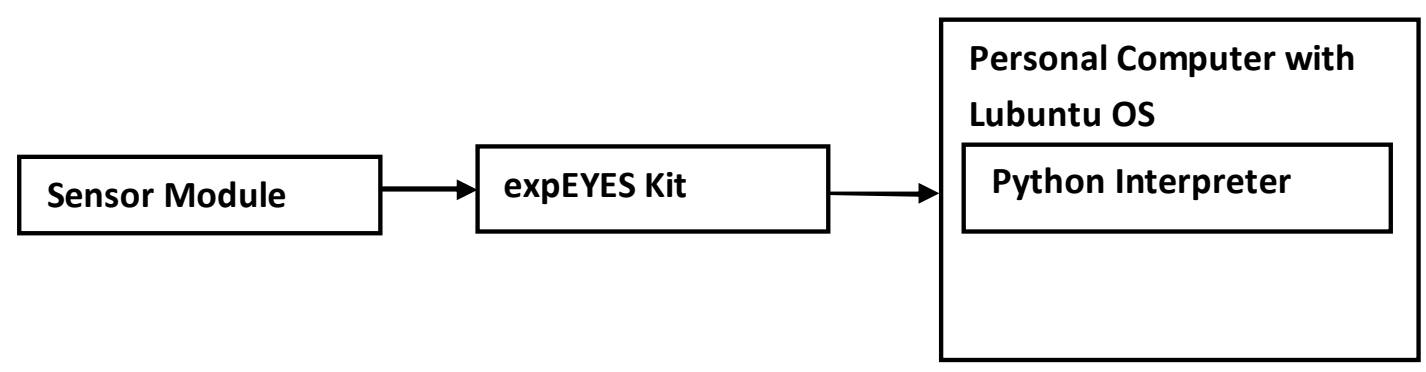

Fig.1 Proposed system for Solar Radiation data Acquisition

\section{Conclusion:}

The present paper is survey of solar radiation measurement and data acquisition system. Various current techniques, noteworthy contribution and instrument used for solar radiation measurement are reviewed. We focused our attention on acquisition techniques. We made a proposal to improve the solar 
radiation data acquisition system so that systems portability will enhance and it will optimize the cost. Implementation will be performed using expEYES board. expEYES board has four channels for analog input and it can be visualized in Graphical user interface at the same time we can record the input with specific time interval by using in built functions of expEYES. Programming will be done in Python language. All proposed improvements will be further investigated.

\section{References:}

1. Balan M., Damian M., Jantschi L. (2008): Solar Radiation Monitoring System, Symposium "Actual Tasks on Agricultural Engineering", Opatija, Croatia, Pp. 507517.

2. Gagliano S., Neri D., Pitrone N., Savalli N., Tina G. (2009): Low-cost solar Radiation Sensing Transducer for Photovoltaic Systems, WSEAS Transactions on Environment and Development, Issue 2, Volume 5. Pp. 119-125.

3. Md. A. Islam, M. L. Palash and Md. H. Rahman (2013): A Microcontroller Based Digital Data Logger System for Solar Radiation Measurement, J.Bangladesh Electron.13(1-2); Pp. 73-79.

4. Painjane P., Nangare R. , Pardeshi A., (2014): Design of Solar Insolation Level Detector and Data Logger, , International Journal of Current Engineering and Technology, Vol.4, No.3 pp.no. 2083-2087

5. Mukaro R., Carelse, Xavier francis(1999): A microcontroller-based data acquisition system for solar radiation and environmental monitoring, Instrumentation and Measurement, IEEE Transactions on , Volume:48, Issue: 6, Pp.1232-1238.

6. Awasthi S., Dubey A., Dr. J. M.Kellar, Dr. P. Mor, Design and simulation of electronic Instruments for Solar Energy measurement systems, International
Journal of Scientific \& Engineering Research, Volume 3, Issue 1, January2012

7. Paulescu M.(2013): Solar Radiation Measurements, Weather Modeling and Forecasting of PV Systems Operation, Green Energy and Technology, SpringerVerlag, London.

8. Medugu D. W., Adisa A. B., Burari F. W. and Abdul'Azeez M. A., (2013): Solar radiation: Correlation between measured andpredicted values in Mubi, Nigeria, International Journal of Science and Technology Education Research Vol. 4(1), pp. 11-17.

9. Manju S., Katoch S. S.,(2014): Design of Photo-voltaic Solar tracking system based on Peripheral Interface Controller , International Journal of Current Engineering and Technology, Vol.4, No.3, Pp. 1800- 1805

10. Ulieru v. D., Cepisca C., Andrei H., Ivanovici T.,(2013): Data Acquisition in Photovoltaic Systems, www. Intechopen.com.

11. Binti F., Abd.Hadi (2012): The Development of Solar Irradiation Levelling System Using Colour Contour Approach, Faculty of Electrical and Electronic Engineering, University Tun Hussein Onn Malaysia.

12. Yang C., Xu Q., Xu X., Zeng P.(2014): Generation of solar radiation data in unmeasurable areas for photovoltaic power station planning, Sch. of Electr. Eng., Southeast Univ., Nanjing, China, PES General Meeting, Conference \& Exposition IEEE, Pp: 1 - 5

13. Gomes, J.M., Ferreira, P.M., Ruano, A.E.(2011): Implementation of an intelligent sensor for measurement and prediction of solar radiation and atmospheric temperature Intelligent Signal Processing (WISP), 2011 IEEE 7th International Symposium, Pp: $1-6$. 